\title{
Modeling the Flash Rate of Thunderstorms. Part II: Implementation
}

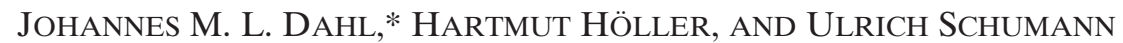 \\ Institut für Physik der Atmosphäre, Deutsches Zentrum für Luft- und Raumfahrt, Oberpfaffenhofen, Germany
}

(Manuscript received 10 November 2010, in final form 23 May 2011)

\begin{abstract}
In Part I of this two-part paper a new method of predicting the total lightning flash rate in thunderstorms was introduced. In this paper, the implementation of this method into the convection-permitting Consortium for Small Scale Modeling (COSMO) model is presented.

The new approach is based on a simple theoretical model that consists of a dipole charge structure, which is maintained by a generator current and discharged by lightning and, to a small extent, by a leakage current. This approach yields a set of four predictor variables, which are not amenable to direct observations and consequently need to be parameterized (Part I).

Using an algorithm that identifies thunderstorm cells and their properties, this approach is applied to determine the flash frequency of every thunderstorm cell in the model domain. With this information, the number of flashes that are accumulated by each cell and during the interval between the activation of the lightning scheme can be calculated.

These flashes are then randomly distributed in time and beneath each cell. The output contains the longitude, the latitude, and the time of occurrence of each simulated discharge.

Simulations of real-world scenarios are presented, which are compared to measurements with the lightning detection network, LINET. These comparisons are done on the cloud scale as well as in a mesoscale region composing southern Germany (two cases each). The flash rates of individual cumulonimbus clouds at the extreme ends of the intensity spectrum are realistically simulated. The simulated overall lightning activity over southern Germany is dominated by spatiotemporal displacements of the modeled convective clouds, although the scheme generally reproduces realistic patterns such as coherent lightning swaths.
\end{abstract}

\section{Introduction}

In this paper, we describe the implementation of the approach developed in Dahl et al. (2011, hereafter referred to as Part I) into the German version of the Consortium for Small Scale Modeling model (COSMO-DE; Doms and Schättler 2002; Baldauf et al. 2011).

Simulating lightning within numerical models is not a new approach. Shortly after deep convective clouds could be simulated (Klemp and Wilhelmson 1978), electrification models were included. In 1982, Rawlins (1982)

\footnotetext{
* Current affiliation: Department of Marine, Earth, and Atmospheric Sciences, North Carolina State University, Raleigh, North Carolina.

Corresponding author address: Dr. Johannes Dahl, Dept. of Marine, Earth, and Atmospheric Sciences, North Carolina State University, Campus Box 8208, Raleigh, NC 27695-8208.

E-mail: johannes_dahl@ncsu.edu
}

considered charging and discharging processes but not lightning channels. Helsdon and Farley (1987) simulated channel propagation using a two-dimensional model. Nowadays, advanced three-dimensional cloud models are equipped with sophisticated electrification schemes (e.g., MacGorman et al. 2001; Mansell et al. 2005). These make use of results from laboratory experiments (e.g., Takahashi 1978; Jayaratne 1998; Saunders and Peck 1998), which have revealed the magnitude and direction of charge transfers during hydrometeor collisions. In these schemes dielectric breakdown is modeled explicitly by initiating lightning channels that exhibit realistic branching and propagation (e.g., MacGorman et al. 2001; Mansell et al. 2002). These parameterizations were implemented in cloud models (Mansell et al. 2005) and in convection-allowing mesoscale models (Barthe et al. 2005). On the other hand, there are comparatively simple schemes that provide the storms' lightning frequencies (Price and Rind 1992; McCaul et al. 2009; Yoshida et al. 2009). The new approach also yields lightning frequencies (where no 
distinction is made between intracloud and cloud-to-ground lightning), but the time and 2D location of each lightning discharge are explicitly assigned in our implementation. This allows for a detailed and comprehensive display of the lightning activity during the simulation period.

The applications of such simulations are manifold. Lightning not only poses a threat to life and property (e.g., Curran et al. 2000), it also has an influence on atmospheric chemistry by its ability to create nitrogen oxides (e.g., Fehr et al. 2004, 2005; Schumann and Huntrieser 2007; Grewe 2009). Moreover, comparison of displays of accumulated simulated and observed lightning provides a convenient way of gaining insight into how realistically the timing and placement of deep convective development is simulated.

The basics of the approach presented in Part I (hereinafter DHS11) will be reviewed in section 2. Section 3 deals with the implementation of this approach into the COSMO-DE model, and in section 4 simulation results are presented. A discussion of these results is offered in section 5, and conclusions are provided in section 6 .

\section{The DHS11 approach}

The DHS11 approach presented in Part I of this study includes a theoretical framework and parameterizations that render it applicable to real-world thunderstorms. What follows is a brief description of the DHS11 approach. The reader is referred to Part I for a detailed presentation of this parameterization.

The theoretical approach is based on the idea that the flash rate is not only determined by the charging rate, but also by the geometry-dependent discharge strength of each lightning flash [in prior approaches, the discharge strength is assumed constant; see Part I; Price and Rind (1992); Blyth et al. (2001)]. Using a simple two-plate capacitor model where the charging and discharging processes are balanced, the flash rate may be expressed as

$$
f=\gamma j \frac{A}{\Delta Q},
$$

where $f$ is the flash rate (in $\mathrm{s}^{-1}$ ), $\gamma$ (lightning efficiency) is a dimensionless factor between zero and one that accounts for the contribution of lightning to the total discharging process, $j$ (in $\mathrm{C} \mathrm{m}^{-2} \mathrm{~s}^{-1}$ ) is the chargingcurrent density, $A$ (in $\mathrm{m}^{2}$ ) is the area of the capacitor plates, and $\Delta Q$ (in $\mathrm{C}$ ) is the lightning charge.

The parameterization part of the approach involves the description of the four variables in Eq. (1),

$$
f=f(A, \gamma, \Delta Q, j)
$$

in terms of the graupel and ice fields. The "graupel region" is defined as the region above the $263-\mathrm{K}$ isotherm where the mass of graupel per unit volume (the "graupel-mass concentration") is at least $0.1 \mathrm{~g} \mathrm{~m}^{-3}$. The "ice region" is defined as the region where the sum of cloud ice and snow is at least $0.1 \mathrm{~g} \mathrm{~m}^{-3}$. The "plate area" $A$ is determined by the horizontal cross-sectional area through the graupel region at the height of the centroid location (implying that the top and bottom plate areas are equal).

The idea underlying the parameterizations is that the graupel region contains negative charge and the ice region contains positive charge, which is based on the noninductive graupel-ice charging mechanism (e.g., Saunders 2008). Moreover, the charging rate $j$ increases with the graupel-mass concentration, and the discharge strength $\Delta Q$ increases as the charge volume increases, as detailed in Part I of this study. The following relations are used to describe the required variables.

The lightning efficiency $\gamma$ is set to $90 \%$ and the lightning charge is determined as a function of charge volume:

$$
\begin{aligned}
& \text { if } \quad 0.0 \leq V<2.5 \mathrm{~km}^{3}, \\
& \text { if } \quad V \geq 2.5 \mathrm{~km}^{3},
\end{aligned}
$$

where $\Delta Q$ is given in coulombs and the mean volume of the two charge regions $V$ is given in cubic kilometers. The generator current density depends on two quantities,

$$
j=\rho v_{g}
$$

where $v_{g}$ is the mean terminal fall velocity of the graupel pellets and $\rho$ is the space charge density in the generator current. This charge density is parameterized as follows:

$$
\rho=\left\{\begin{array}{lll}
0.0 & \text { if } & 0.0 \leq m_{g}<0.1 \mathrm{~g} \mathrm{~m}^{-3} \\
4.467 \times 10^{-10}+3.067 \times 10^{-9} m_{g} & \text { if } & 0.1 \leq m_{g} \leq 3.0 \mathrm{~g} \mathrm{~m}^{-3} \\
9.8 \times 10^{-9} & \text { if } & m_{g}>3.0 \mathrm{~g} \mathrm{~m}^{-3}
\end{array}\right.
$$


where $m_{g}$ is the cell's maximum graupel-mass concentration (in $\mathrm{g} \mathrm{m}^{-3}$ ). To describe the terminal velocity of the graupel, first its diameter needs to be determined, which is also parameterized using the graupel-mass concentration:

$$
D_{g}\left(m_{g}\right)=\left\{\begin{array}{lll}
0.0 & \text { if } & 0.0 \leq m_{g}<0.1 \mathrm{~g} \mathrm{~m}^{-3} \\
1.833 \times 10^{-3}+3.333 \times 10^{-3} m_{g} & \text { if } & 0.1 \leq m_{g} \leq 3.0 \mathrm{~g} \mathrm{~m}^{-3} \\
0.012 & \text { if } & m_{g}>3.0 \mathrm{~g} \mathrm{~m}^{-3}
\end{array}\right.
$$

where $D_{g}$ is the graupel diameter (in $\mathrm{m}$ ). Then, the terminal velocity of the graupel pellets is given by (Heymsfield and Kajikawa 1987)

$$
v_{g}=422.0 D_{g}^{0.89}
$$

where $v_{g}$ is the magnitude of the terminal graupel fall velocity (in $\mathrm{m} \mathrm{s}^{-1}$ ). Qualitatively, the prediction of this theory is that thunderstorms with a small horizontal extent and weak graupel content above the $263-\mathrm{K}$ isotherm exhibit small flash rates and vice versa.

\section{Lightning detection and definition of a "flash"}

To compare the lightning simulations with observations, the lightning detection network, LINET, is used (Betz et al. 2009). This system detects signals in the very low-frequency/low-frequency (VLF/LF) range and uses a time-of-arrival technique to determine the three-dimensional position of the discharge. The reported LINET "strokes" are grouped into "flashes" such that all events that occur within $1 \mathrm{~s}$ and in an area with a radius of $10 \mathrm{~km}$ are binned into a single flash, as was also done in Part I of this study.

\section{Description of the model and the new algorithm}

COSMO-DE is a fully compressible, convectionallowing numerical weather prediction model. In this study a Lin-type single-moment, six-category bulk microphysics scheme was used, which predicts mixing ratios of water vapor, cloud water, rain, cloud ice, snow, and graupel (Doms and Schättler 2002; Baldauf et al. 2011). The time-independent grid is terrain following, becoming quasi-horizontal with increasing altitude. The vertical grid spacing varies from about $50 \mathrm{~m}$ in the lowest model layers to about $1000 \mathrm{~m}$ toward the domain top, which is at $22500 \mathrm{~m}$. The horizontal grid spacing is about $2.8 \mathrm{~km}\left(0.025^{\circ}\right)$. The model domain includes Germany and parts of the adjacent countries, and it is nested in the domain of the European-scale model COSMO-EU. The time integration was performed using a two-time-level Runge-Kutta scheme with a large time step of $25 \mathrm{~s}$. In this study we used version 4.6 of COSMO-DE.

In the operational setup, radar data are introduced into the simulation via latent-heat nudging (Stephan et al. 2008). Here, the model runs were started at 0000 UTC, and although 0000 UTC observations were used to initialize the model, no nudging was performed; the boundary data after initialization were provided by COSMO-EU.

The lightning scheme was activated every $15 \mathrm{~min}$, which was a compromise, as longer intervals would have led to unrealistic lightning patterns (see also section 5), while shorter intervals would have sharply increased the computation time. More information about the COSMO model may be found in Baldauf et al. (2011), Steppeler et al. (2003), and the references therein. ${ }^{1}$

\section{Implementation of the lightning scheme}

Based on the previous section, only knowledge about the spatial distribution of the graupel-mass and ice-mass concentrations as well as of the temperature is necessary to implement the DHS11 approach. The variables that need to be determined by the algorithm are

- the 263-K level,

- the centroid position of each graupel region,

- the horizontal cross-sectional area of each graupel region,

- each storm's maximum graupel-mass concentration, and

- the layer thickness of each graupel and ice region.

If these quantities are known, the DHS11 flash rate can be determined. Figure 1 schematically shows how the required parameters are found by the algorithm, as explained in the following.

First, each graupel region is identified using a "blob identification" or "labeling" algorithm (Hoshen and Kopelman 1976, hereafter HK76; Constantin et al. 1997). The HK76 algorithm was originally developed for

\footnotetext{
${ }^{1}$ Extensive online documentation may be found on the COSMO Web site (http://www.cosmo-model.org).
} 


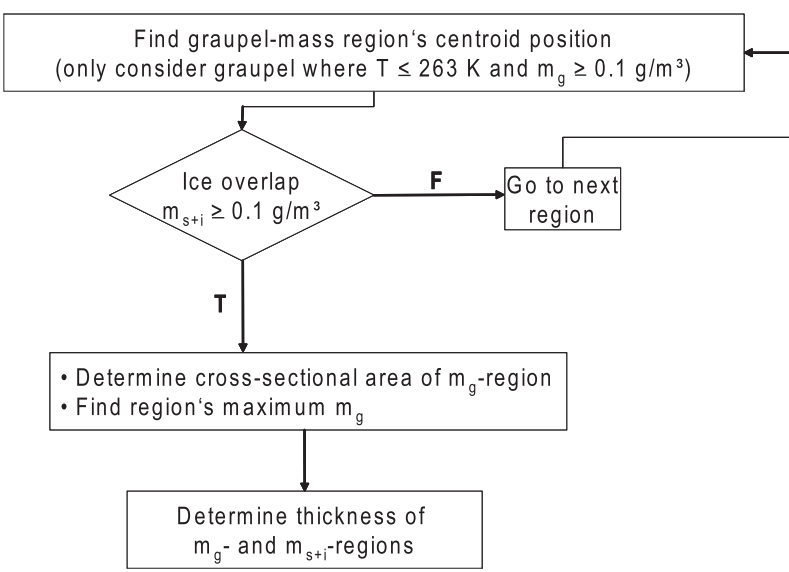

FIG. 1. Pseudoflowchart of the part of the algorithm that determines the cloud properties. The graupel-mass concentration is abbreviated with $m_{g}$ and the ice-mass concentration (containing the cloud ice and snow categories) with $m_{s+i}$. See text for discussion.

application in percolation theory and is an efficient way of labeling contiguous regions that fulfill certain properties in a 3D domain (e.g., graupel-mass concentration $m_{g} \geq$ $0.1 \mathrm{~g} \mathrm{~m}^{-3}$ ). All grid points that fulfill this criterion are assigned the value -1 (these grid points are said to be "occupied"), while all others are set to zero. Then this 3D binary array is scanned, and each occupied grid point is assigned a unique positive number. If an occupied grid point is encountered that has a previously labeled neighbor, then that occupied grid point is assigned the label of its neighbor. The main challenge is to handle two or more previously labeled regions that, while scanning the array, are found to belong to a common cluster. To achieve this cluster-fragment linking in an efficient way, the labels of all involved clusters are not immediately reassigned. Instead, a list is maintained that keeps record of each cluster's label and its connection to another cluster. In a second pass through the array, proper labeling is performed, using the information contained in the list. Parallelization of the HK76 algorithm was carried out as proposed by Constantin et al. (1997).

Once each graupel region is labeled, its centroid position is determined, and the existence of ice crystals above each graupel region is verified. This condition includes the possibility that the ice region may be somewhat displaced horizontally from the graupel region. In the calculations, this offset is neglected and the regions are treated as though they are vertically stacked. If an ice region exists over the graupel region, these regions are considered to be part of a cumulonimbus cloud, and it is assumed that electrification is occurring. Otherwise, the cloud is not considered to have the potential of producing lightning. This assumption may be violated in extreme cases when the updraft is sheared so strongly that the ice region is displaced well downstream from the graupel region. However, no such case was observed in the simulations.

The required geometric properties of the cloud include the horizontal cell area, approximated by the horizontal cross section through the graupel region, and the charge volume.

To determine this volume, the horizontal crosssectional area of the graupel region at its centroid position is multiplied by the average thickness of the graupel and ice regions. This thickness is determined by the vertical extent of these regions at the centroid location of the graupel region.

Once the location of each cell and its properties (location, horizontal area, maximum graupel-mass concentration, charge volume) are known, the flash rate is calculated for each cell.

The next step is to determine the accumulated flashes of each cell between two calls of the lightning scheme. If it is called every $\Delta T$ seconds, the accumulated number of flashes of the cell labeled $k$, is

$$
n_{k}=\Delta T f_{k},
$$

where $n_{k}$ is the total number of flashes of the $k$ th cell and $f_{k}$ is the flash rate of the $k$ th cell. As now the accumulated number of discharges for each cell is known, the flashes are temporally distributed. A list is created containing entries for all the flashes occurring in the domain during the time interval between two calls of the scheme. This list contains pseudorandomly generated times in the interval between the lightning-scheme activations. The first $n_{k}$ entries are taken to represent the times of the flashes produced by the first $(k=1)$ cell, and so forth for all $k$. This way, instantaneous fluctuations of the individual flash rates are simulated.

Next, the $n_{k}$ flashes per cell are spatially distributed around and beneath each cell in a circular manner. This distribution is realized in plane polar coordinates. A pseudorandom number generator is used to spread the $n_{k}$ flashes within the radius $R_{k}$ around each cell and in random azimuthal directions. This radius is expressed as an angular distance in degrees ${ }^{2}$ and is given by the equivalent circular radius of the graupel area:

$$
R_{k}=\frac{180^{\circ}}{\pi r_{e}} \sqrt{\frac{A_{k}}{\pi}},
$$

\footnotetext{
${ }^{2}$ This is because the horizontal gridpoint locations in COSMO$\mathrm{DE}$ are defined in (rotated) geographical coordinates.
} 


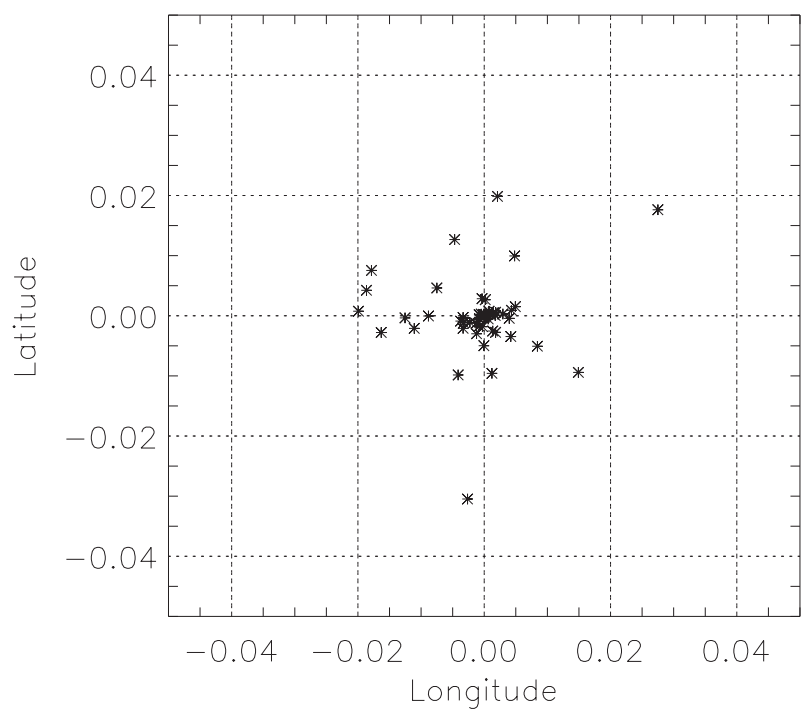

FIG. 2. Example of random flash locations for $n_{k}=50$. The locations are marked by asterisks and the units of the $x$ and $y$ axes are degrees. The centroid of the cell is located at $(0,0)$. An angular distance of $0.05^{\circ}$ corresponds to about $5.6 \mathrm{~km}$ (note that the geographical coordinates in COSMO-DE are rotated such that the equator runs through southern Germany).

where $r_{e}$ is the earth's radius and $A_{k}$ is the plate area of the $k$ th cell. Gauss weighting is applied to reduce the lightning occurrence toward the edge of the cell:

$$
r_{i}=R_{k} \exp \left[-(a i)^{2}\right], \quad \text { where } i=1, \ldots, n_{k} .
$$

Here, $r_{i}$ is the angular distance in degrees of the $i$ th discharge from the cell centroid, $R_{k}$ is the plate radius (also expressed as angular distance), and $a=(\sigma \sqrt{2})^{-1}$ with $\sigma=0.4 n_{k}$. Figure 2 shows how lightning locations are distributed around a centroid position located at the geographical coordinates $(\lambda, \phi)=(0,0)$ for $n_{k}=50$. This procedure is repeated for every cell.

This completes the algorithm, and after minor postprocessing the final output is a list containing the time and the geographical coordinates of every simulated discharge. A pseudoflowchart shown in Fig. 3 sums up the main steps of the lightning routine.

\section{COSMO-DE-SPECIFIC ADDITIONS}

As pointed out by Bryan et al. (2003), a horizontal grid spacing of $2.8 \mathrm{~km}$ is insufficient to resolve convective clouds. Over the course of this work, we found that in COSMO-DE the convective clouds generally tend to be too wide, roughly by a factor of 2 . Moreover, the graupel particles in the microphysics scheme are best described as "densely rimed snow" or "light graupel particles." As the conversion from riming snow to graupel is initiated rather early, excessively wide graupel regions may result

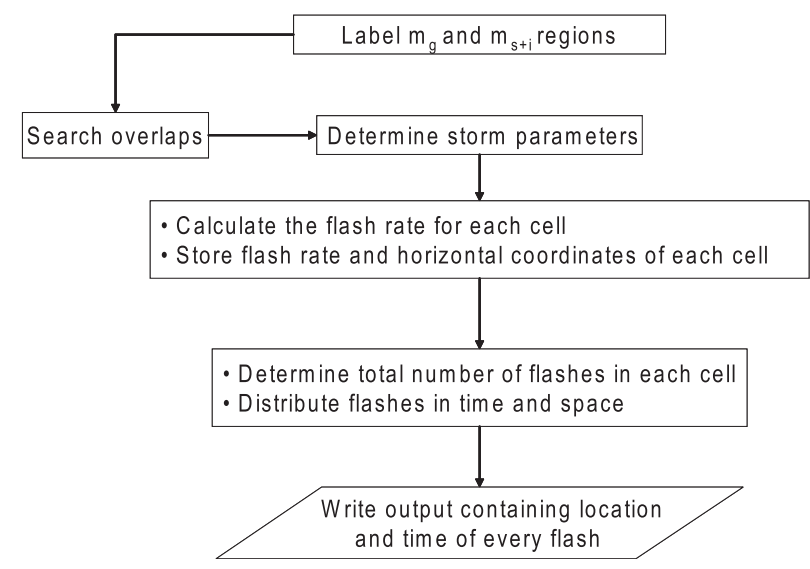

FIG. 3. Pseudoflowchart showing the main steps of the lightning scheme. See text for detailed descriptions.

(A. Seifert 2010, personal communication). Although this problem could have been circumvented by introducing larger thresholds to define the graupel regions, this would have filtered out weak convective clouds, yielding overall unrealistic results. Other definitions of the cloud width (e.g., via the updraft width) were equally unsuccessful. The solution was to reduce the area of the graupel region $A$, before inserting it into the flash-rate equation. In turn, the graupel-mass concentration was somewhat increased.

The following corrections were found (using polarimetric radar data; see Part I) to yield largely realistic storm sizes and graupel-mass concentrations, independent of storm size and intensity:

$$
m_{\mathrm{gc}}=1.2 m_{\mathrm{g}}
$$

and

$$
A_{c}=0.25 A \text {, }
$$

where $m_{\mathrm{gc}}$ is the corrected graupel-mass concentration and $A_{c}$ is the corrected area.

Clearly, these corrections are quite crude, and they are merely employed to make the DHS11 approach applicable to COSMO-DE.

Moreover, it was found that the DHS11 approach overestimates the flash rates of mesoscale convective systems (MCSs) by a factor of about 2 (Fig. 6 in Part I). A simple ad hoc correction for this shortcoming is introduced for the COSMO-DE implementation. Between $15-$ and $\sim 45-\mathrm{km}$ cell diameter, the flash rate is artificially reduced to $40 \%$ of the original value. This threshold is based on Fig. 6 in Part I and shifts the three MCS observations closer to the 1:1 relationship. The gradual decrease ensures that, for example, large isolated supercells are not significantly affected by the correction. This correction is given by 


$$
c=\left\{\begin{array}{ll}
1.0 & \text { if } D \leq 15 \mathrm{~km} \\
0.4+0.6 \exp \left(-[0.085(D-15.0)]^{2}\right) & \text { if } \quad D>15 \mathrm{~km}
\end{array},\right.
$$

where $c$ is the dimensionless correction factor. This correction is entirely artificial and only serves to render the simulation results more realistic in cases of large MCSs. It is not proposed to remedy the inability of DHS11 to predict MCS flash rates accurately.

\section{Results}

In this section lightning simulations of COSMO-DE are presented. Two aspects of the simulations will be considered: individual simulated thunderstorm cells and the total lightning activity over southern Germany.

\section{a. Individual thunderstorms}

To compare individual modeled cells with their realworld analogs, only cases could be considered where the modeled cells developed in the correct synoptic regime, (nearly) at the correct time, and where they exhibited a largely realistic structural evolution. This assessment is somewhat subjective, but only those cases were considered where the association between modeled and realworld convection was quite clear. Two extreme cases at both ends of the discrete (i.e., non-MCS) storm spectrum for central Europe are presented.

\section{1) 22 August 2008}

The first case involves an isolated supercell that developed over southeastern Germany on the afternoon of 22 August 2008. This case covers the high-intensity end of the spectrum of discrete thunderstorms, both in terms of storm organization and flash production. On its eastward track, the cell evolved into a severe, hail-producing supercell, as reported by eyewitnesses and supported by radar data (not shown). In the evening hours, another cell appeared in close vicinity to the original cell both in the model and in reality. As will be shown in the next subsection, the development in the model was somewhat delayed and farther east than the observed storm, but the overall evolution was realistic enough that a direct comparison is justified.

The mean modeled and observed lightning frequencies were compared within several time intervals as summarized in Table 1. The observed flash rates of the two nearby cells range from about 10 to $20 \mathrm{~min}^{-1}$ and from about 30 to $60 \mathrm{~min}^{-1}$, respectively. These frequencies are accurately reproduced, including the slight strengthening
TABLE 1. Comparison of the flash rates of the simulated (COSMO) and observed (LINET) supercells on 22 Aug 2008.

\begin{tabular}{lccc}
\hline \hline Source & $\begin{array}{c}\text { Time interval } \\
(\text { UTC) }\end{array}$ & $\begin{array}{c}\text { Flash rate } \\
(\text { cell 1, min }\end{array}$ & $\begin{array}{c}\text { Flash rate } \\
\left(\text { cell 2, } \text { min }^{-1}\right)\end{array}$ \\
\hline LINET & $1900-1930$ & 12 & 38 \\
COSMO & $1900-1930$ & 10 & 33 \\
LINET & $1915-1945$ & 64 & - \\
COSMO & $1915-1945$ & 17 & 45 \\
LINET & $1930-1945$ & 22 & 58 \\
COSMO & $1930-1945$ & 23 & 54
\end{tabular}

trend of the cells. The periods were selected such that the observed cells were in the domain where LINET data were available and that the simulated cell had reached a quasi-steady state.

Between 1915 and 1945 UTC, the two observed cells were so close to each other that only one "flash cell" with a flash rate of $64 \mathrm{~min}^{-1}$ was identified (a 2D version of the HK76 algorithm was used to detect coherent lightning-density regions). Using the sum of the flash rates of both simulated cells, a lightning rate of $62 \mathrm{~min}^{-1}$ is obtained.

\section{2) 2 APRIL 2008}

On 2 April 2008, rather shallow polar-air cumulonimbi spread across southern Germany and produced short-lived but intense snow and graupel showers. Occasionally, this convection would support a lightning discharge. This scenario represents the weak end of electrified convection for central Europe.

In this case it was impossible to single out a certain cell and compare it with its model analog. The reason is that a large number of cells developed, all individually short lived, so that no unique one-to-one mapping between real-world and modeled cells could be established. To circumvent these difficulties, the average lightning frequency over a number of cells was taken (both observed and simulated). The domain selected for this purpose comprised much of southern Germany. The requirements were that this domain did not contain convection associated with a different synoptic regime and that most of both the observed and the simulated convection was contained in this domain. First, the mean flash rate of each cell in a certain time period was summed up. As the number of thunderstorm cells was known, the average flash rate per cell could be determined. This calculation was performed for both observed and simulated cells and for several time intervals. The overall temporal evolution of the convection in the model was realistic, so that the flash rates were compared at the same times. These 
TABLE 2. Comparison between averaged observed (LINET) and averaged modeled (COSMO) flash rates on 2 Apr 2008. Also shown are the numbers of cells $n$ over which the flash-rate average was taken.

\begin{tabular}{lccr}
\hline \hline Source & $\begin{array}{c}\text { Time interval } \\
\text { (UTC) }\end{array}$ & $\begin{array}{c}\text { Mean flash } \\
\text { rate }\left(\min ^{-1}\right)\end{array}$ & $n$ \\
\hline LINET & $1330-1400$ & 0.06 & 37 \\
COSMO & $1330-1400$ & 0.07 & 79 \\
LINET & $1400-1415$ & 0.15 & 8 \\
COSMO & $1400-1415$ & 0.13 & 50 \\
LINET & $1400-1430$ & 0.07 & 14 \\
COSMO & $1400-1430$ & 0.06 & 76 \\
\hline
\end{tabular}

results are shown in Table 2 . The majority of the cells produced about one flash every $15 \mathrm{~min}\left(0.07 \mathrm{~min}^{-1}\right)$, though in the selected 15-min interval, a small fraction of the cells exhibited flash rates as high as $0.5 \mathrm{~min}^{-1}$ (not shown). This increased the average flash rate in the 15-min interval to more than $0.1 \mathrm{~min}^{-1}$. Interestingly, this behavior was observed in reality as well as in the model simulation, but the simultaneous increase in this particular time window very likely is coincidental. The total number of flashing cells in this simulation is overestimated (Table 2).

\section{b. Overall lightning activity}

While the former investigation was devoted to cloudscale lightning activity, now the overall lightning development over southern Germany is assessed. Two cases have been selected. This choice was motivated by the different patterns of behavior of the model convection in each case.

\section{1) 22 August 2008}

The evolution of the lightning activity on 22 August 2008 based on LINET measurements is depicted in Fig. 4, revealing a broad "lightning track" that extends from southeastern Germany into Austria. Figure 5 shows the simulated lightning activity. The lightning swath is also present in the simulation, but it is displaced to the east and south, and the associated thunderstorms developed a few hours too late in the model. However, the presence of a distinct track justifies the direct comparison of the simulated and observed cells in the previous subsection.

The model initiated scattered convection with much lightning over the western part of the domain, where only minimal lightning activity was observed with

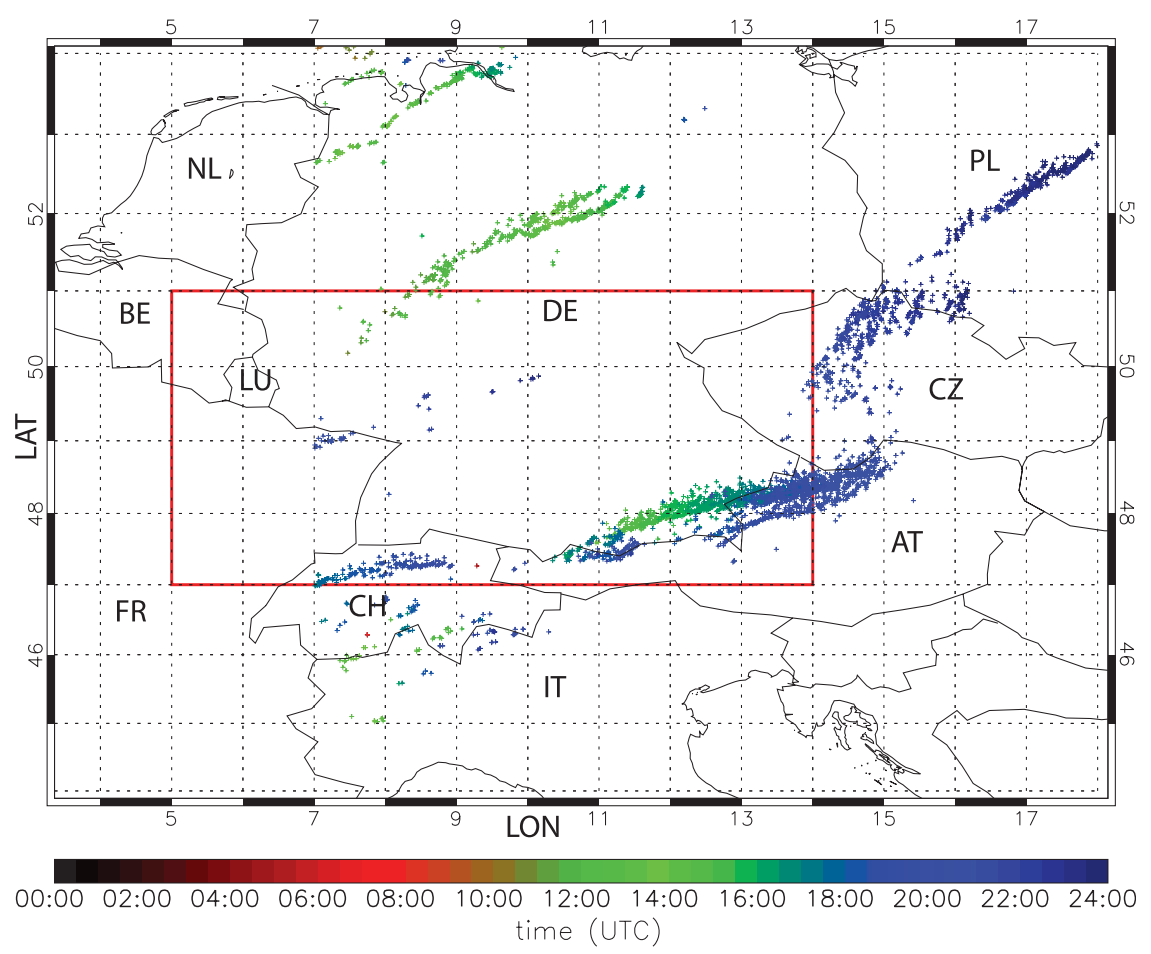

FIG. 4. LINET flashes on 22 Aug 2008. The plus signs represent discharge locations; time is color coded. The red rectangle indicates the subdomain used for the statistical analysis of the data. Country codes are shown to facilitate orientation: AT, Austria; BE, Belgium; CH, Switzerland; CZ, Czech Republic; DE, Germany (Deutschland); FR, France; IT, Italy; LU, Luxemburg; NL, Netherlands; and PL, Poland. 


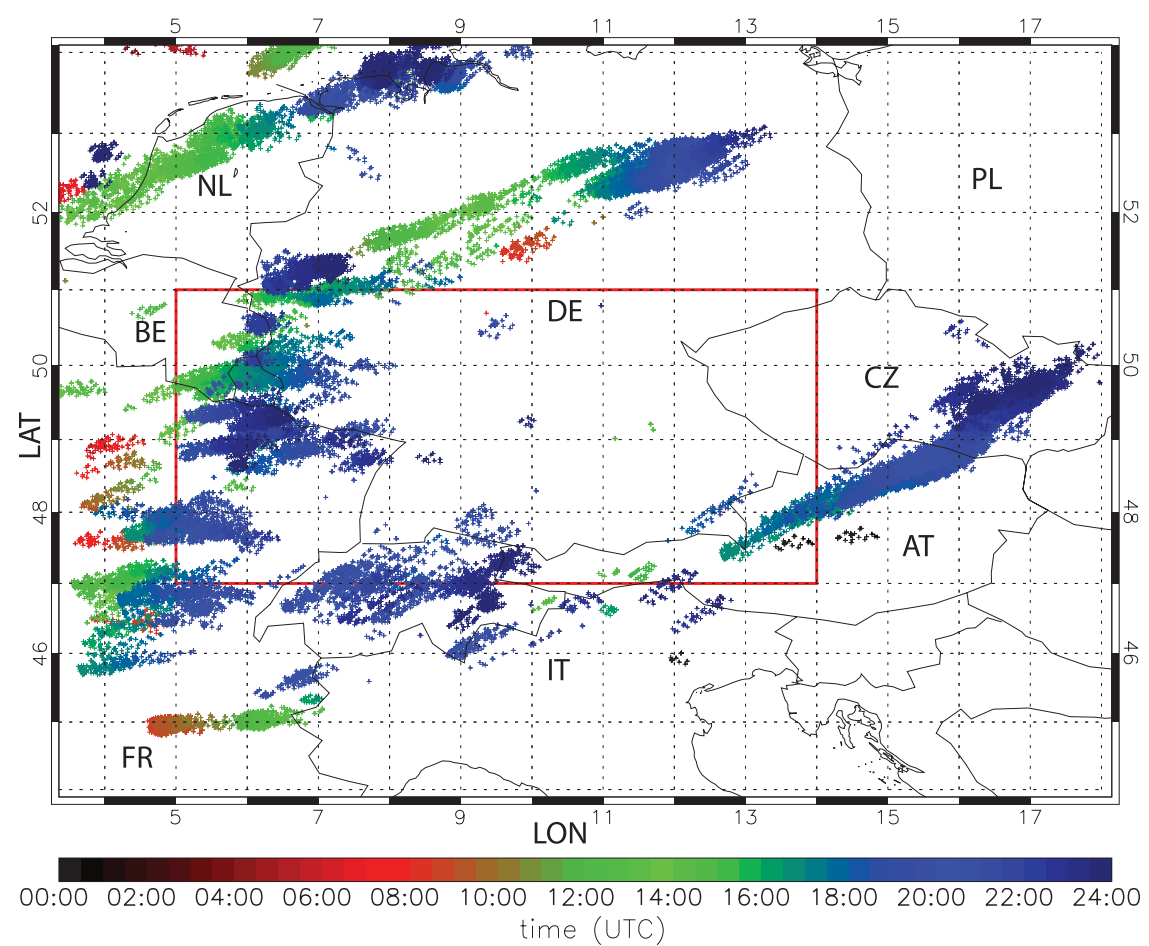

FIG. 5. COSMO-DE flashes based on DHS11 on 22 Aug 2008. The plus signs represent discharge locations; time is color coded. The red rectangle indicates the subdomain used for the statistical analysis of the data. Country codes (defined in the caption of Fig. 4) are shown to facilitate orientation.

LINET. The temporal evolution of the observed and modeled lightning activity over southern Germany on that day is shown in Figs. 6 and 7 , respectively. The total number of accumulated flashes in the simulation and in the domain under consideration was 14354 (simulated) versus 8489 (observed).

This difference is due mainly to convection that develops in the simulation in the western parts of the domain in the evening hours. The fact that the lightning activity commences during the afternoon hours was correctly simulated.

\section{2) 5 JULY 2009}

On 5 July 2009, scattered thunderstorms developed with diurnal heating (and dissipated with a lack thereof) in a rather quiescent synoptic regime. Figure 8 shows an overview of observed flashes and Fig. 9 depicts the simulated lightning activity based of the DHS11 parameterization for that day.

The most striking feature in the COSMO-DE simulation is spurious excessive nocturnal convection. In the afternoon, too little convection develops over southeastern Germany. This is also reflected in the histogram plots in Figs. 10 and 11, which display the temporal evolution of observed and modeled lightning, respectively. The total number of flashes is overestimated in the simulation by a factor of about 7 (61 073 simulated versus 8893 observed flashes). These results are discussed in the next section.

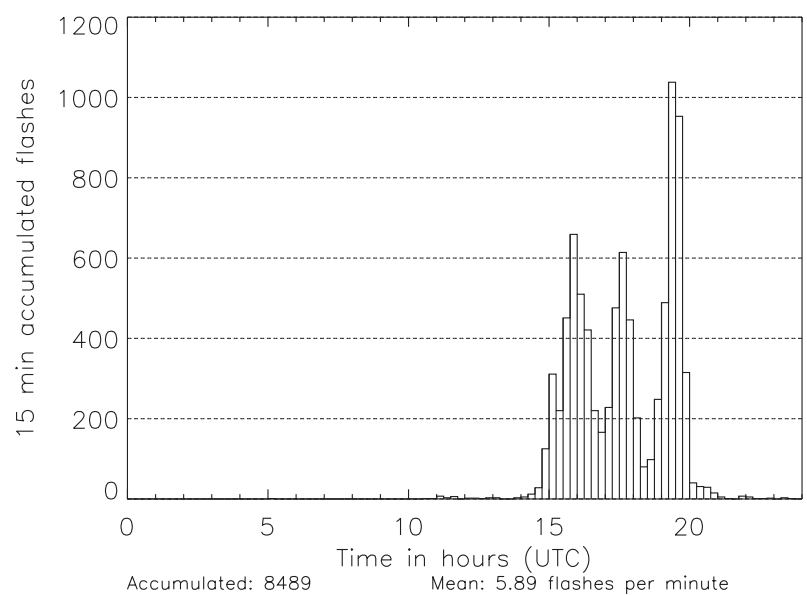

FIG. 6. Histogram plot of observed lightning activity over southern Germany on 22 Aug 2008, showing the 15-min accumulated flashes. The total number of flashes and the mean flash rate in the $24-\mathrm{h}$ period are plotted at the bottom of the figure. 


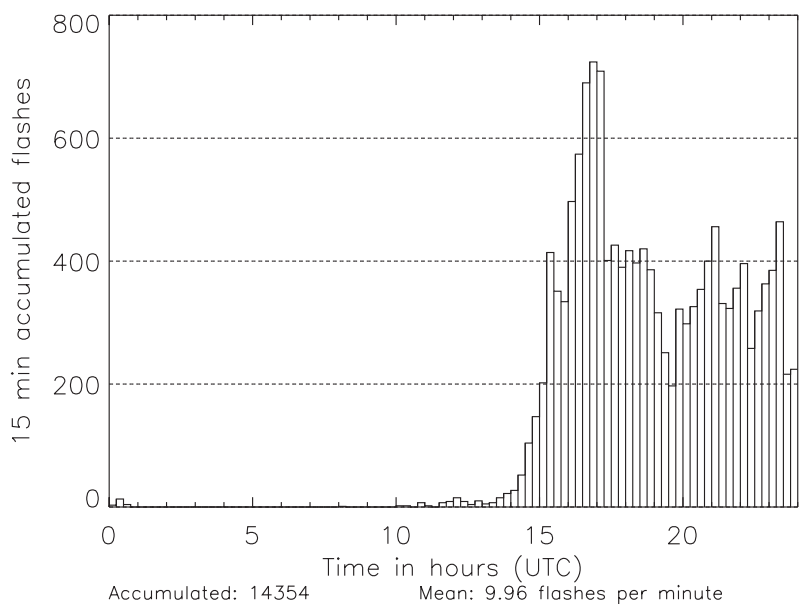

FIG. 7. Histogram plot of and simulated lightning activity using the DHS11 scheme, showing the 15-min accumulated flashes. The total number of flashes and the mean flash rate in the 24-h period are plotted at the bottom of the figure.

\section{Discussion}

The lightning scheme presented in this paper is based on the framework proposed in Part I. As such, it is based on thunderstorm cell entities and the individual flash locations are distributed in the vicinity and underneath these cells. However, if strong low-level mesoscale forcing for ascent is present, "slablike" convection may result (James et al. 2005; Bryan and Fritsch 2000), where the graupel regions of individual cells may merge into one elongated region. In these cases, broad swaths of lightning may be observed. In the current implementation, a long, linear graupel region would be treated as a circular region with the same area as the elongated region. The flashes would be distributed circularly under the centroid of this region. Consequently, the linear nature of the convective system would not be apparent in the lightning simulations. However, in central Europe these systems are favored in the cold season (Gatzen et al. 2011) when often the forecast challenge is whether or not lightning will occur at all. Even if the current scheme may not reproduce the lightning swath accurately in these particular situations, it may aid in deciding whether lightning should be forecast. Moreover, oftentimes these lines exhibit a slabular nature only at low levels while individual cell cores are present farther aloft at altitudes that are relevant for identifying the graupel regions (James et al. 2005).

The circular distribution of flashes around the cell is expected to result in increasingly unrealistic results as the activation interval of the lightning scheme (900 s in this study) is increased. The accumulated number of flashes per interval becomes larger while the centroids of

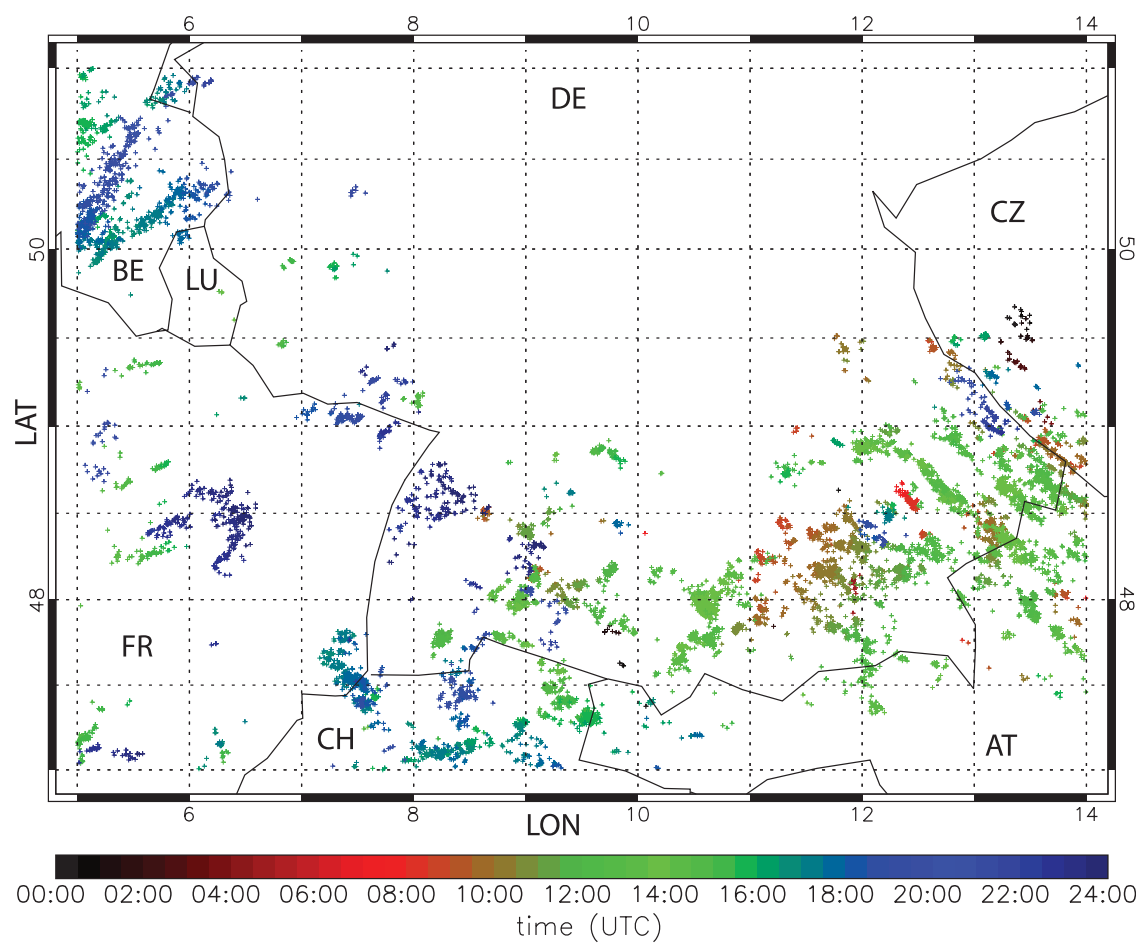

FIG. 8. LINET flashes on 5 Jul 2009. The plus signs represent discharge locations; time is color coded. Country codes (see Fig. 4) are shown to facilitate orientation. 


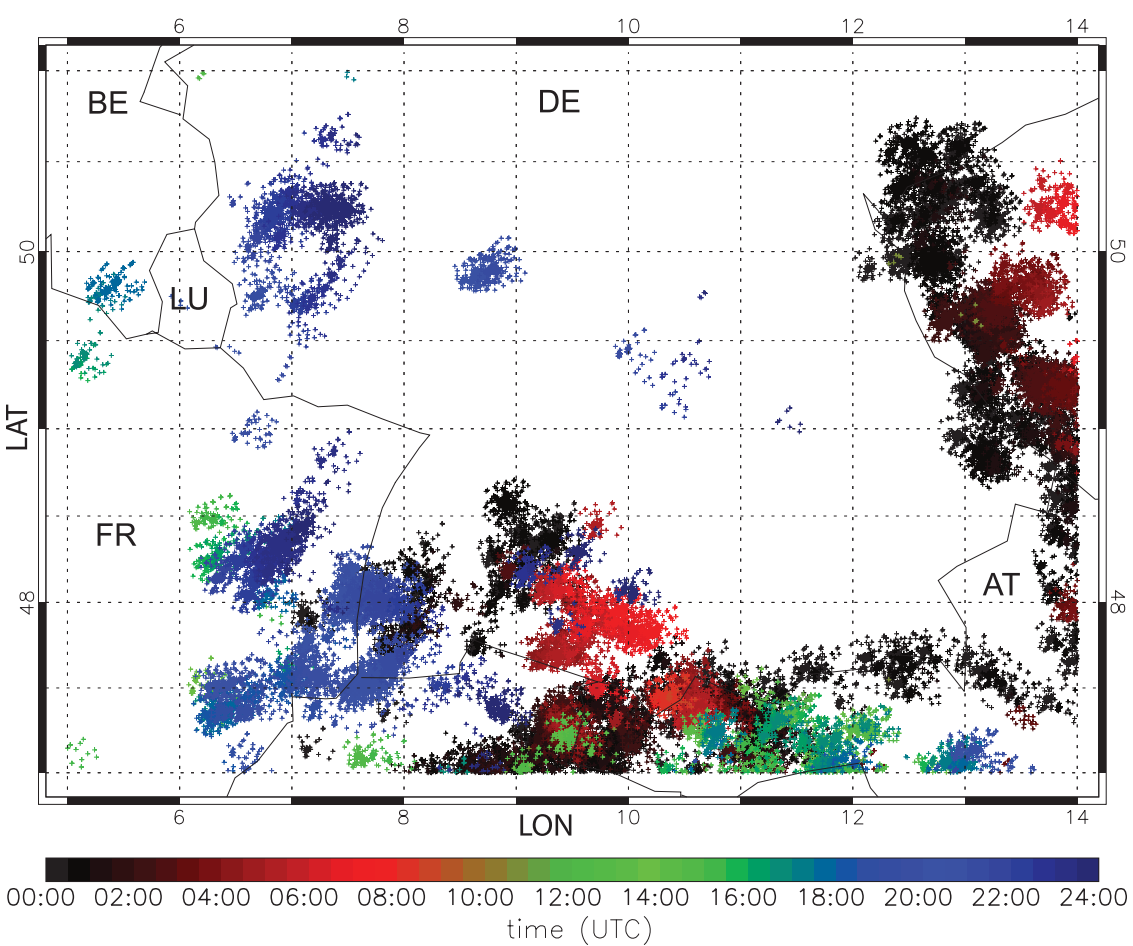

FIG. 9. COSMO-DE flashes based on DHS11 on 5 Jul 2009. The plus signs represent discharge locations; time is color coded. Country codes (see Fig. 4) are shown to facilitate orientation.

each cell at the activation times become farther separated. Since the distance over which the flashes are distributed around the cell depends on the instantaneous size of the cell and not on the number of the flashes (which is related to the activation interval of the scheme), this may result in gaps in the lightning path. The same is true if the cells exhibit small flash rates but fast motion (the striated paths over northern Italy in Fig. 5 are an example of this). In earlier implementations, attempts were undertaken to remedy this effect by considering the storms' motion to facilitate an upstream flash distribution. However, this resulted in unrealistic lightning patterns because it was impossible to determine storm motion accurately based on environmental parameters (to remedy this problem, a cell-tracking algorithm would be required). Reducing the activation interval would reduce the likelihood of gaps in the lightning tracks, and result in smoother changes of the lightning-path width belonging to the individual storms.

Given that the accumulated flashes between the activations of the scheme are extrapolated linearly, it is implicitly assumed that the lightning rates do not change considerably in that period. Increasing the activation interval beyond the convective time scale (of order $15 \mathrm{~min}$ ) will increasingly violate this assumption (e.g., new cells may develop at a flank of a given storm). The choice of an activation interval of $900 \mathrm{~s}$ in this study is a compromise between these factors and computational expenses.

It is worth emphasizing that although the goal of simulating individual flash locations was to obtain realistic lightning patterns, only the number of flashes per

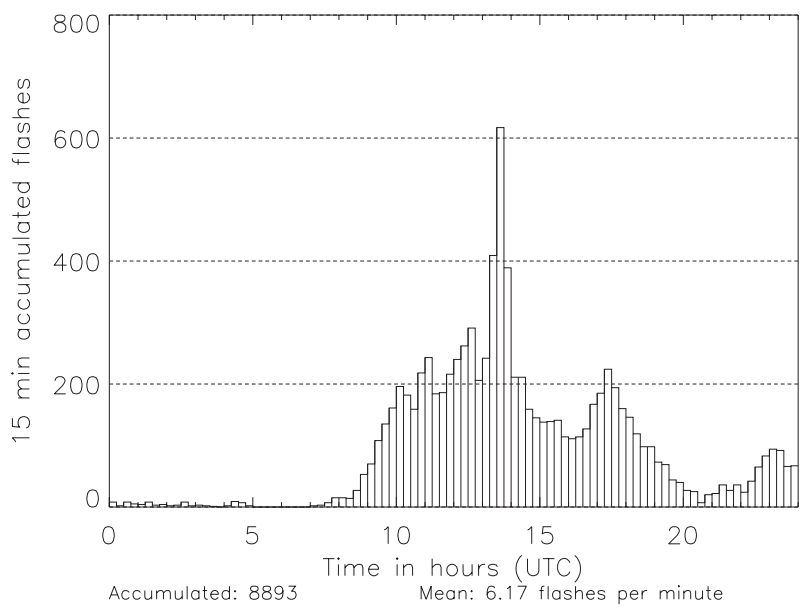

FIG. 10. Histogram plot of observed lightning activity, showing the 15-min accumulated flashes. The total number of flashes and the mean flash rate in the 24 -h period are plotted at the bottom of the figure. 


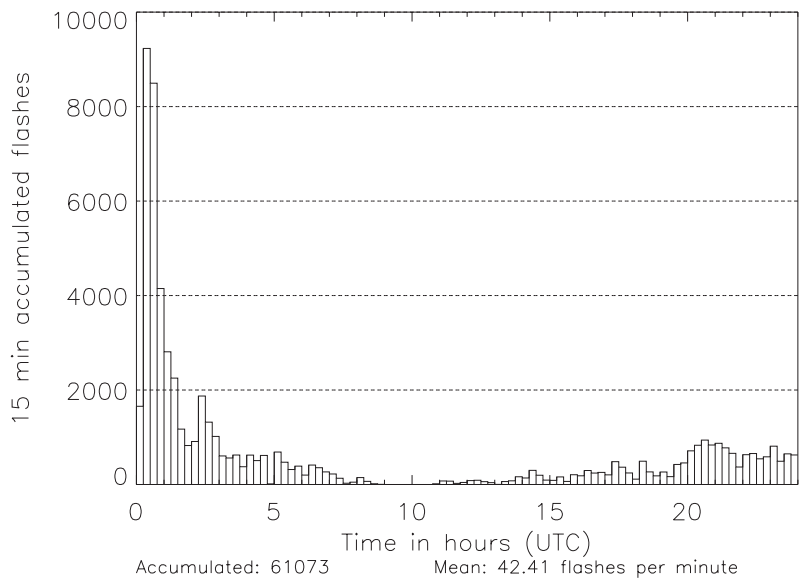

FIG. 11. Histogram plot of the simulated lightning activity using the DHS11 scheme, showing the 15-min accumulated flashes. The total number of flashes and the mean flash rate in the 24 -h period are plotted at the bottom of the figure.

cell is predicted. The subcloud-scale and subactivationinterval details of the lightning discharges are randomly generated to emulate observed patterns.

In the current implementation, the convective clouds generated in COSMO-DE had to be "resized" to apply the DHS11 approach. This correction would need to be adjusted if a different model, a different grid spacing, or a different microphysics scheme was employed, and may be dropped if convection-resolving grid spacing (Bryan et al. 2003) was used, assuming an accurate representation of the microphysics. The parameterization itself would not need to be adjusted.

\section{a. Individual cells in COSMO-DE}

In two scenarios involving isolated thunderstorms at the extreme ends of the intensity spectrum, the flash rates were simulated accurately in COSMO-DE. This is consistent with the application of the DHS11 approach to observed thunderstorms (Part I of this study). Since the two investigated cases were at the opposite ends of the intensity spectrum of central European storms, these findings provide confidence that individual thunderstorm clouds in the simulations generally exhibit realistic flash rates.

The lightning simulations directly reflect the properties of the simulated graupel and ice regions. If there are large discrepancies between observed and simulated individual flash rates, it may be a hint that the convective clouds are not properly represented in the model (as is the case in this study).

\section{b. Lightning evolution over southern Germany}

The discrepancies between the overall observed and simulated lightning activity may be due to erroneous lightning-frequency predictions while the convective cells are correctly simulated; or they may be due to erroneous convective development in the model, while the lightning frequencies are correctly simulated, or both. However, it is difficult to quantify these contributions, because every observed cell would have to be compared to its simulated counterpart, which most of the time is impossible. The encouraging results of the two cases of individual thunderstorms are a hint that a large contribution to the error in the overall lightning evolution is due to the wrong timing and placement of the simulated storms. The lightning simulations directly inherit the shortcomings of the model to simulate the correct number and placement of convective cells. This property may be used to test the ability of the model to reproduce convective scenarios accurately. The cases presented herein suggest that COSMO-DE tends to simulate too many lightning-producing clouds (e.g., Figs. 4 and 5).

Altogether, it is not surprising that COSMO-DE does not capture every detail of the convective development, given the long simulation periods before convective initiation occurs (usually more than $12 \mathrm{~h}$ ). Other mesoscale models have similar problems, which directly affect the quality of the lightning predictions (McCaul et al. 2009).

An interesting observation is the extensive nocturnal convection that develops in the simulation early on 5 July 2009. Figure 12 shows the simulated vertical sum of the graupel-mass concentration $1 \mathrm{~h}$ after model initialization on 5 July 2009. Widespread graupel areas are visible, consistent with the strong lightning activity at that time. The reason for this development is likely tied to the assimilation of radar data into the model (Stephan et al. 2008). This procedure adjusts the latent heating profiles in the model in proportionality to the inferred rain rate. This imparted latent-heat release initiates the convection. Although no latent-heat nudging was performed in the simulations in this study, the initial analysis field does contain the assimilated radar data. The simulations performed in the course of this study suggest that this type of artificially triggered convection may be common in weakly forced and weakly capped situations. This effect is well apparent in the lightning simulations.

Despite the inability of the model to capture the details of the convective evolution, the lightning forecasts are still useful within a forecasting context. The simulations may be considered to offer one possible scenario given a certain environment. Moreover, recent research has focused on temporally integrated displays of the simulated convective activity (Kain et al. 2010). Standard model output such as radar-reflectivity fields only provide an instantaneous picture, and accumulated precipitation fields may include nonconvective precipitation in convection-permitting models. The output of the 


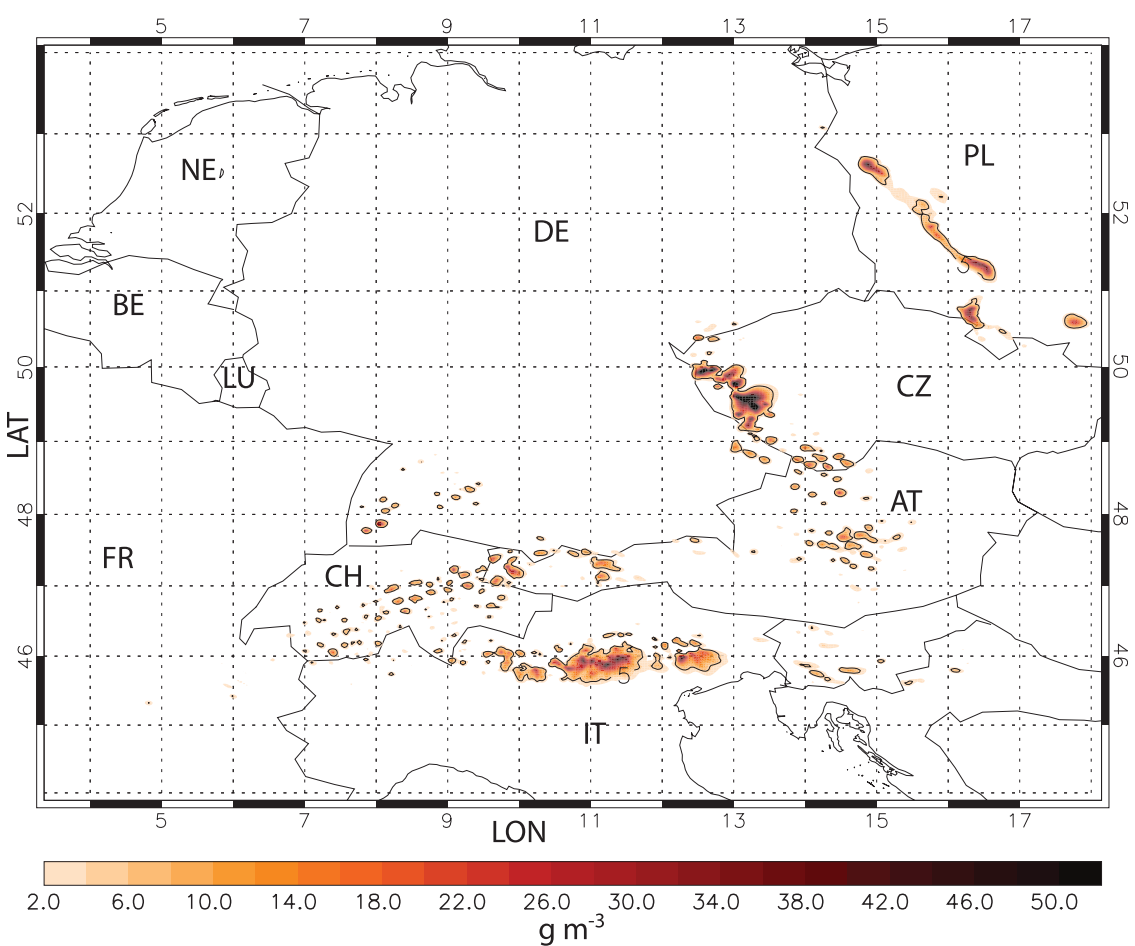

FIG. 12. Vertical sum of the COSMO-DE graupel-mass concentration in $\mathrm{g} \mathrm{m}^{-3}$ at $1 \mathrm{~h}$ after initialization (0100 UTC) on $5 \mathrm{Jul}$ 2009. The strong graupel accumulations are consistent with the simulated early morning lightning activity on that day. Country codes (see Fig. 4) are shown to facilitate orientation.

lightning scheme is another way of displaying integrated information about the overall thunderstorm activity through the simulation period.

\section{Conclusions}

The DHS11 lightning flash rate parameterization has been implemented in the convection-permitting COSMODE operational forecast model. A cluster-detection algorithm identifies contiguous graupel and ice regions, which are used to define cumulonimbus clouds. Subsequently, the geometries of the cells, their maximum graupel-mass concentration, and their centroid locations are specified. With this information, the number of accumulated flashes per cell, occurring during the interval between each activation of the lightning scheme, is determined. In the last step, the flashes are randomly distributed in time and around the centroids of the cells, yielding the time and the horizontal location of every flash as output.

The cloud-scale investigation of two cases of simulated discrete cumulonimbus clouds reveals that the flash rates of individual cells in these scenarios are realistically simulated. As these cases represent two extremes in terms of lightning production, we are confident that intermediate cases are also handled well, although this was not explicitly tested herein. The simulated total lightning activity over a mesoscale region (southern Germany) is found to be dominated by the wrong placement and timing of the convective clouds in the two investigated cases. However, the scheme generally reproduces realistic patterns such as coherent lightning swaths.

The lightning scheme allows for a comprehensive and detailed display in one graphic of where the model develops thunderstorms, which is not easily achieved with standard output fields. The lightning simulations can be used to test properties of the simulated convective clouds and whether the modeled storms develop at the correct time and location. Within the forecasting context, the simulations offer one possible convective scenario in the given environment, which is useful even if the details of the timing and location of the storms are not exactly reproduced.

Acknowledgments. We thank Drs. Christian Keil, Axel Seifert, and Ulrich Schättler for their help whenever technical problems were encountered. Professor H.-D. Betz kindly provided the LINET data. The computational resources were provided by the German Weather Service (DWD), which is gratefully acknowledged. Also, 
we thank the two anonymous reviewers for their careful comments and the Convective Storms Group (NCSU) for their support during the preparation of the manuscript. This study was funded by the DLR project "Wetter und Fliegen."

\section{REFERENCES}

Baldauf, M., A. Seifert, J. Förstner, D. Majewski, M. Raschendorfer, and T. Reinhardt, 2011: Operational convective-scale numerical weather prediction with the COSMO model: Description and sensitivities. Mon. Wea. Rev., in press.

Barthe, C., G. Molinie, and J. Pinty, 2005: Description and first results of an explicit electrical scheme in a 3D cloud resolving model. Atmos. Res., 76, 95-113.

Betz, H. D., K. Schmidt, P. Laroche, P. Blanchet, W. P. Oettinger, E. Defer, Z. Dziewit, and J. Konarski, 2009: LINET-An international lightning detection network in Europe. Atmos. Res., 91, 564-573.

Blyth, A. M., H. J. Christian, K. Driscoll, A. M. Gadian, and J. Latham, 2001: Determination of ice precipitation rates and thunderstorm anvil ice contents from satellite observations of lightning. Atmos. Res., 59, 217-229.

Bryan, G. H., and J. M. Fritsch, 2000: Moist absolute instability: The sixth static stability state. Bull. Amer. Meteor. Soc., 81, 1207-1230.

—- J. C. Wyngaard, and J. M. Fritsch, 2003: Resolution requirements for the simulation of deep moist convection. Mon. Wea. Rev., 131, 2394-2416.

Constantin, J., M. Berry, and B. Vander Zanden, 1997: Parallelization of the Hoshen-Kopelman algorithm using a finite state machine. Int. J. High. Perform. Comput. Appl., 11, 34-48.

Curran, E. B., R. L. Holle, and R. E. Lopez, 2000: Lightning casualties and damages in the United States from 1959 to 1994. J. Climate, 13, 3448-3464.

Dahl, J. M. L., H. Höller, and U. Schumann, 2011: Modeling the flash rate of thunderstorms. Part I: Framework. Mon. Wea. Rev., 139, 3093-3111.

Doms, G., and U. Schättler, 2002: A description of the nonhydrostatic regional model LM. Part I: Dynamics and numerics. Deutscher Wetterdienst, 134 pp. [Available online at http://cosmo-model.org.]

Fehr, T., H. Höller, and H. Huntrieser, 2004: Model study on production and transport of lightning-produced $\mathrm{NO}_{\mathrm{x}}$ in a EULINOX supercell storm. J. Geophys. Res., 109, D09102, doi:10.1029/2003JD003935.

—, N. Dotzek, and H. Höller, 2005: Comparison of lightning activity and radar-retrieved microphysical properties in EULINOX storms. Atmos. Res., 76, 167-189.

Gatzen, P. P., T. Púčik, and D. Ryva, 2011: Two cold-season derechoes in Europe. Atmos. Res., 100, 740-748.

Grewe, V., 2009: Impact of lightning on air chemistry and climate. Lightning: Principles, Instruments and Applications, H.-D. Betz, U. Schumann, and P. Laroche, Eds., Springer, 537-549.

Helsdon, J. H. J., and R. D. Farley, 1987: A numerical modeling study of a Montana thunderstorm: 2. Model results versus observations involving electrical aspects. J. Geophys. Res., 92, $5661-5675$
Heymsfield, A., and M. Kajikawa, 1987: An improved approach to calculating terminal velocities of plate-like crystals and graupel. J. Atmos. Sci., 44, 1088-1099.

Hoshen, J., and R. Kopelman, 1976: Percolation and cluster distribution. I. Cluster multiple labeling technique and critical concentration algorithm. Phys. Rev., 14B, 3438-3445.

James, R. P., J. M. Fritsch, and P. M. Markowski, 2005: Environmental distinctions between cellular and slabular convective lines. Mon. Wea. Rev., 133, 2669-2691.

Jayaratne, E., 1998: Density and surface temperature of graupel and the charge separation during ice crystal interactions. J. Geophys. Res., 103, 13 957-13961.

Kain, J. S., S. R. Dembek, S. J. Weiss, J. L. Case, J. J. Levit, and R. A. Sobash, 2010: Extracting unique information from highresolution forecast models: Monitoring selected fields and phenomena every time step. Wea. Forecasting, 25, 1536-1542.

Klemp, J. B., and R. B. Wilhelmson, 1978: The simulation of threedimensional convective storm dynamics. J. Atmos. Sci., 35, 1070-1096.

MacGorman, D., J. Straka, and C. Ziegler, 2001: A lightning parameterization for numerical cloud models. J. Appl. Meteor. 40, 459-478.

Mansell, E. R., D. R. MacGorman, C. L. Ziegler, and J. M. Straka, 2002: Simulated three-dimensional branched lightning in a numerical thunderstorm model. J. Geophys. Res., 107, 4075, doi:10.1029/2000JD000244.

, D. MacGorman, C. Ziegler, and J. Straka, 2005: Charge structure and lightning sensitivity in a simulated multicell thunderstorm. J. Geophys. Res., 110, D12101, doi:10.1029/ 2004JD005287.

McCaul, E., Jr., S. J. Goodman, K. M. LaCasse, and D. J. Cecil, 2009: Forecasting lightning threat using cloud-resolving model simulations. Wea. Forecasting, 24, 709-729.

Price, C., and D. Rind, 1992: A simple lightning parameterization for calculating global lightning distributions. J. Geophys. Res., 97, 9919-9933.

Rawlins, F., 1982: A numerical study of thunderstorm electrification using a three-dimensional model incorporating the ice phase. Quart. J. Roy. Meteor. Soc., 108, 779-800.

Saunders, C. P. R., 2008: Charge separation mechanisms in clouds Space Sci. Rev., 137, 335-353.

— rime accretion rate on charge transfer during crystal/graupel collisions. J. Geophys. Res., 103, 13 949-13 956.

Schumann, U., and H. Huntrieser, 2007: The global lightninginduced nitrogen oxides source. Atmos. Chem. Phys., 7, 38233907.

Stephan, K., S. Klink, and C. Schraff, 2008: Assimilation of radarderived rain rates into the convective-scale model COSMODE at DWD. Quart. J. Roy. Meteor. Soc., 134, 1315-1326.

Steppeler, J., G. Doms, U. Schaettler, H. W. Bitzer, A. Gassmann, U. Damrath, and G. Gregoric, 2003: Meso-gamma scale forecasts using the nonhydrostatic model LM. Meteor. Atmos. Phys., 82, 75-96.

Takahashi, T., 1978: Riming electrification as a charge generation mechanism in thunderstorms. J. Atmos. Sci., 35, 1536-1548.

Yoshida, S., T. Morimoto, T. Ushio, and Z. Kawasaki, 2009: A fifthpower relationship for lightning activity from Tropical Rainfall Measuring Mission satellite observations. J. Geophys. Res., 114, D09104, doi:10.1029/2008JD010370. 